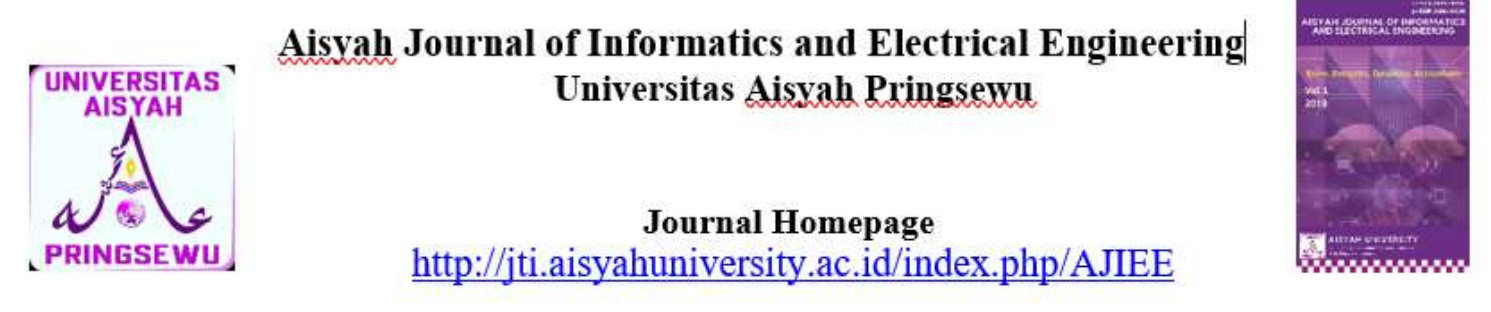

\title{
MODEL BERBASIS K-NEAREST NEIGHBOR \\ DALAM PENENTUAN PENERIMA BEASISWA
}

\author{
Zulkifli $^{1}$, Ilham Ubaidillah ${ }^{2}$ \\ 1,2Program Studi Teknik Informatika, Fakultas Teknologi dan Informatika \\ Universitas Aisyah Pringsewu \\ e-mail: zulkiflist31@gmail.com
}

\begin{abstract}
Abstrak
Sistem pengambilan keputusan untuk menentukan penerima beasiswa BBM masih belum optimal yaitu menggunkan sistem seleksi berkas. Setiap ada pengajuan beasiswa yang diajukan mahasiswa, maka untuk menganalisa berkas pengajuan beasiswa BBM membutuhkan waktu yang relatif lama. Model ini untuk mengetahui tingkat akurasi antara metode nearest neighbor dan naive bayesian classification dalam menentukan penerima beasiswa BBM. Saat ini pemilihan penerima beasiswa BBM dilakukan manual dan melalui hasil IPK Saja. Penilaian dengan jumlah mahasiswa yang banyak sangat menyulitkan pihak perguruan tinggi STIKes Aisyah Pringsewu, hasil penilaian dan pertimbangan pengambilan keputusan cenderung lebih subjektif, sehingga cenderung terjadi kesalahan dalam pengambilan keputusan akhir mahasiswa mana yang layak mendapatkan beasiswa BBM. Oleh karena itu Diperlukan sistem pendukung keputusan yang akan memudahkan pemilihan siswa berprestasi dan membuat keputusan yang efektif dan efisien. $K$ NEAREST NEIGHBOR merupakan metode yang akan digunakan dalam memberikan referensi kepada pihak perguruan tinggi STIKes Aisyah Pringsewu dalam menentukan penerima beasiswa BBM. Sistem pendukung keputusan ini merupakan alat bantu yang dapat memberikan solusi dalam proses pemilihan mahasiswa peneriam beasiswa BBM secara komputerisasi dengan harapan lebih efektif dan efisien serta tepat dan akurat. Hasil penelitian membuktikan bahwa model ini mampu membantu perguruan tinggi STIKes Aisyah Pringsewu dalam proses seleksi pemilihan mahasiswa yang akan mendapatkan beasiswa BBM dengan tingkat akurasi $80 \%$
\end{abstract}

Kata kunci: Beasiswa, SPK, K-NEAREST NEIGHBOR. 


\section{Pendahuluan}

Pendidikan merupakan sesuatu yang sangat penting, namun tidak semua orang dapat menempuh pendidikan sesuai yang diharapkan. Salah satu permasalahan pendidikan di Indonesia adalah tingginya biaya pendidikan khususnya untuk memperoleh gelar sarjana. Biaya yang diperlukan tidak sedikit untuk menyelesaikan studi di perguruan tinggi sehingga memperoleh gelar sarjana.

Untuk mengatasi masalah tingginya biaya pendidikan, salah satu cara yang dilakukan oleh pemerintah lewat Direktorat Jenderal Pendidikan Tinggi Kementerian Pendidikan Nasional dan Kebudayaan, mengupayakan pemberian bantuan biaya pendidikan bagi mahasiswa yang orang tua atau walinya kurang mampu membiayai pendidikan, dalam bentuk Bantuan Biaya Mahasiswa (BBM).

Beasiswa merupakan hal yang sangat didambakan oleh setiap mahasiswa, sehingga hampir setiap ada peluang untuk memperoleh beasiswa, banyak mahasiswa yang mengumpulkan berkas lamaran beasiswa. Dengan banyaknya peminat beasiswa, secara tidak langsung akan mengakibatkan proses seleksi menjadi lebih lama. Hal ini dikarenakan data yang banyak dan prosedur penilaian berkas mahasiswa yang masih dilakukan secara manual. Disisi lain, kriteria yang dinilai relatif tidak berubah, sehingga mengakibatkan data-data yang digunakan untuk menilai sering terjadi pengulangan atau memiliki sebuah kesamaan antara data lama dan data baru.

Sistem pendukung pengambilan keputusan merupakan bagian dari sistem informasi berbasis komputer (termasuk sistem berbasis pengetahuan) yang dipakai untuk mendukung dalam pengambilan keputusan pada suatu organisasi Pendekatan statistis mulai digunakan untuk membantu menyelesaikan permasalahan yang mengandung ketidakpastian dan robustness. Soft computing merupakan salah satu pendekatan penyelesaian masalah tersebut. (Zhang, 2007).

\section{Tinjauan Pustaka}

\subsection{Sistem Pendukung Keputusan}

Sistem Pendukung Keputusan (SPK) atau Decision Support System (DSS) adalah sebuah sistem yang mampu memberikan kemampuan pemecahan masalah maupun kemampuan pengkomunikasian untuk masalah dengan kondisi semi terstruktur dan tak terstruktur. Sistem ini digunakan untuk membantu pengambilan keputusan dalam situasi semi terstruktur dan situasi yang tidak terstruktur, dimana tak seorangpun tahu secara pasti bagaimana keputusan seharusnya dibuat (Turban, 2001).

SPK bertujuan untuk menyediakan informasi, membimbing, memberikan prediksi serta mengarahkan kepada pengguna informasi agar dapat melakukan pengambilan keputusan dengan lebih baik.SPK merupakan implementasi teoriteori pengambilan keputusan yang telah diperkenalkan oleh ilmu-ilmu seperti operation research dan menegement science, hanya bedanya adalah bahwa jika dahulu untuk mencari penyelesaian masalah yang dihadapi harus dilakukan perhitungan iterasi secara manual (biasanya untuk mencari nilai minimum, maksimum, atau optimum), saat ini computer PC telah menawarkan kemampuannya untuk menyelesaikan persoalan yang sama dalam waktu relatif singkat.

\subsection{Algoritma Nearest Neighbor}

Algoritma Nearest Neighbor Retrieval (knearest neighbor atau k-NN) adalah sebuah algoritma untuk melakukan klasifikas terhadap objek berdasarkan data pembelajaran yang jaraknya paling dekat dengan objek tersebut. Kasus khusus di mana klasifikasi diprediksikan berdasarkan data pembelajaran yang paling dekat (dengan kata lain, $k=1$ ) disebut algoritma nearest neighbor. Algoritma nearest neighbor berdasarkan pada proses pembelajaran menggunakan analogi atau learning by analogi. Training sampelnya dideskripsikan dalam bentuk atribut numerik n-dimensi. Tiap sampel mewakili sebuah titik pada ruang n-dimensi. Dengan cara ini, semua training sampel disimpan pada pola 
ruang n-dimensi. Ketika diberikan "unknown" sampel, k-nearest neighbor classifier mencari pola ruang $\mathrm{K}$ training sampel yang paling dekat "unknown" sampel tersebut. K training sampel ini adalah $k$ nearest neighbor dari unknown sampel. Unknown sampel ditetapkan dengan class yang paling umum diantara $k$ nearest neighborsnya. Ketika $\mathrm{k}=1$, unknown sampel ditetapkan dengan class dari training sampel yang paling dekat dengan pola ruangnya. (Kusrini dan Lutfi, 2009)

Similarity $(\mathrm{T}, \mathrm{S})=\frac{s 1 x w i+s 2 x w 2+\cdots+s n x w n}{w 1+w 2+\cdots+w n}$

$=\underline{\sum_{i=1}^{n} f(T i, S i) x w i}$

WN

Keterangan :

$\mathrm{T}=$ Kasus baru

$\mathrm{S}=$ Kasus yang ada dalam database

$\mathrm{n}=$ Jumlah atribut dalam setiap kasus

$\mathrm{f}=$ fungsi similarity untuk fitur i dalam kasus

$\mathrm{T}$ dan $\mathrm{S}$

$\mathrm{s}=$ Nama atribut ( Nilai Kemiripan atau nilai kedekatan )

$\mathrm{w}=$ Weight $($ Bobot Yang diberikan $)$

\section{Metodologi Penelitian}

Metodologi penelitian adalah cara yang digunakan dalam memperoleh berbagai data untuk diproses menjadi informasi yang lebih akurat sesuai permasalahan yang akan diteliti. Metodologi penelitian digunakan sebagai pedoman dalam pelaksanaan penelitian agar hasil yang dicapai tidak menyimpang dari tujuan yang telah dilakukan sebelumnya. Metodologi penelitian yang digunakan dalam penyusunan Tesis ini akan melalui beberapa tahapan yang membentuk sebuah alur yang sistematis.

\subsection{Subjek Penelitian}

Lokasi penelitian ini dilakukan di Perguruan Tinggi STIKes Aisyah Pringsewu, yang akan membahas tentang program Beasiswa BBM. Adapun tempat penelitian yang akan dilaksanakan adalah di STIKes Aisyah Pringsewu.

\subsection{Tahapan Penelitian}

Metodologi penelitian dalam pengerjaan penelitian ini meliputi beberapa tahapan, seperti ditunjukan pada gambar 3.1.

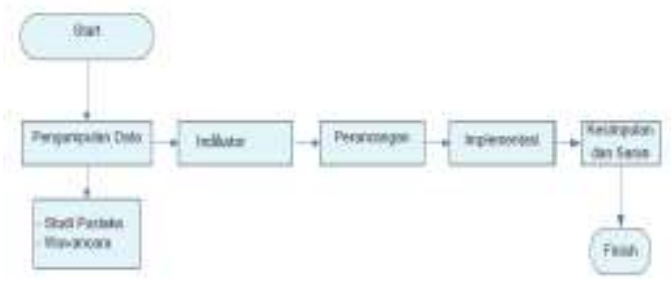

Gambar 3.1 Tahapan Penelitian

\subsubsection{Metode Pengumpulan Data}

Metode pengumpulan data memiliki peran yang sangat penting, karena metode pengumpulan data akan menentukan kualitas dan keakuratan data yang akan dikumpulkan selama proses penelitian. Dengan berbagai macam metode pengumpulan data, peneliti akan menggunakan metode sebagai berikut :

a. Wawancara / Interview

Teknik pengumpulan data dengan melakukan Tanya jawab langsung dengan bagian BAAK, mengenai tentang alur sistem beasiswa BBM yang berjalan. Teknik wawancara yang dilakukan adalah wawancara tidak terstruktur agar peneliti leluasa menggali informasi selengkap dan sedalam mungkin dalam suasana rileks.

b. Studi Pustaka (Library Research Method)

Merupakan cara pengumpulan data yang berhubungan dengan materi penelitian dengan membaca buku atau browsing di internet.

\subsubsection{Indikator}

Indikator adalah suatu ukuran tidak langsung dari suatu kondisi. Indikator adalah variabel yang membantu kita dalam mengukur perubahan perubahan yang terjadi baik secara langsung maupun secara tidak langsung 
Indikator disini yaitu variabel awal syarat penerimaan beasiswa BBM masyarakat ekonomi rendah dan memiliki IPK tertinggi, dan pada sistem yang akan dirancang ada berbagai indikator antara lain (1) IPK (2) Semester (3) Pekerjaan Orang Tua (4) Jumlah Tanggungan Orang Tua (5) Penghasilan Orang Tua (6) KWH PLN (7) Kelayakan.

Dalam sistem dilakukan proses perhitungan dari membuat data training, data testing, data testing, perhitungan probabilitas masing-masing kriteria dan penentuan keputusan yang didapat dari perhitungan global dari masing-masing kriteria. untuk metode algoritma $K$ Nearest Neighbor proses perhitungan dilakukan dengan data training yang berupa angka, karena algoritma $K$ Nearest Neighbor memiliki prinsip kerja mencari jarak terdekat antara data yang akan dievaluasi. Hasil akhirnya adalah memberikan hasil keputusan alternatif yang dapat dijadikan pertimbangan dalam proses mengambil keputusan saat menentukan calon penerima beasiswa BBM sesuai dengan kriteria dari pihak akademik.

\subsection{Jenis Penelitian}

Penelitian ini bersifat deskriptif kuantitatif. Deskriptif adalah desain riset yang lebih menekankan pada penentuan frekuensi terjadinya sesuatu atau sejauh mana suatu variabel saling berhubungan, merupakan penelitian yang bisa menggambarkan karakteristik dari obyek, manusia, kelompok, organisasi maupun lingkungan dengan kata lain penelitian ini harus bisa menggambarkan yang berkenaan dengan apa, siapa, dimana dan bagaimana.

\subsection{Perancangan}

Pada perancangan sistem pendukung keputusan, tahap perancangan adalah membuat rincian sistem hasil dari indikator menjadi bentuk perancangan agar dipahami oleh pengguna.

Setelah mempelajari tentang metode-metode mengenai sistem pendukung keputusan pada bab sebelumnya, bab ini akan lebih difokuskan pada penjelasan mengenai sistem pendukung keputusan yang akan diterapkan untuk menentukan penerima beasiswa BBM.

\subsubsection{Perancangan Sistem}

Sistem yang akan dirancang ini terdiri dari tiga komponen utama yaitu:

\subsubsection{Subsistem Managemen Data}

Subsistem manajemen data merupakan komponen SPK yang berupa basis data yang berisi kumpulan data-data hasil penelitian di lapangan yang sesuai dengan keperluan pengambilan keputusan. Basis data tersebut berupa data-data tentang data training dan data testing telah ditetapkan.

Pada pemilihan calon penerima beasiswa BBM pada STIKes Aisyah Pringsewu ini dibutuhkan data untuk pembuatan sistem ini, yaitu:

a. Data Training

Yaitu nama-nama dua puluh dua mahasiswa STIKes Aisyah Pringsewu yang dijadikan sampel penulis dalam pemilihan calon penerima beasiswa BBM pada STIKes Aisyah Pringsewu.

\section{b. Data Kriteria}

Untuk mendapatkan hasil keputusan yang berkualitas dalam penelitian tentang sistem pendukung keputusan multi kriteria, pemilihan kriteria dilakukan berdasarkan sumber dan kesesuaian terhadap lingkungan penelitian. Adapun penentuan kriteria dilakukan dalam penelitian ini adalah sebagai berikut:

\section{IPK}

Kriteria ini merupakan data mengenai IPK mahasiswa STIKes Aisyah Pringsewu.

\section{Semester}


Kriteria ini merupakan data mengenai semester aktif mahasiswa STIKes Aisyah Pringsewu.

3. Pekerjaan Orang Tua

Kriteria ini merupakan data mengenai pekerjaan dari Orang tua mahasiswa STIKes Aisyah Pringsewu

4. Jumlah Tanggungan Orang Tua

Kriteria ini merupakan data jumlah tanggungan yang dibiayai orang tua mahasiswa STIKes Aisyah Pringsewu.

5. Penghasilan Orang Tua

Kriteria ini merupakan data mengenai seberapa besar jumlah penghasilan dari orang tua mahasiswa STIKes Aisyah Pringsewu.

6. KWH Listrik

Kriteria ini merupakan data pemakaian KWH Listrik pada rumah mahasiswa STIKes Aisyah Pringsewu.

7. Kelayakan

Kriteria ini merupakan data mahasiswa STIKes Aisyah Pringsewu yang sudah ada dengan data yang berisi LAYAK dan TIDAK LAYAK.

\section{Hasil dan Pembahasan}

\subsection{Penerapan Model Algortima $K$ -}

Nearest Neighbor

Penerapan model algoritma $K$ -

Nearest Neighbor akan menggunakan studi kasus pemilihan penerima beasiswa pada STIKes Aisyah Pringsewu dengan sampel data mahasiswa yang ada, adapun kriteria yang digunakan:

Tabel 3.1 Kriteria Model K-Neares

Neighbor Penerimaan Beasiswa BBM

\begin{tabular}{|lc|}
\multicolumn{1}{c}{ KRITERIA } & $\begin{array}{c}\text { KETERANG } \\
\text { AN }\end{array}$ \\
\hline IPK & ATRIBUT \\
\hline SEMESTER & ATRIBUT \\
\hline $\begin{array}{l}\text { TANGGUNGAN ORANG } \\
\text { TUA }\end{array}$ & ATRIBUT \\
\hline $\begin{array}{l}\text { PENGHASILAN ORANG } \\
\text { TUA }\end{array}$ & ATRIBUT \\
\hline KWH PLN & ATRIBUT \\
\hline KELAYAKAN & LABEL \\
\hline
\end{tabular}

Sumber : BAAK Perguruan Tinggi STIKes Aisyah Pringsewu.

\subsubsection{Data Testing Model Algoritma $K$ -} Nearest Neighbor

Data testing merupakan data pengujian yang akan digunakan sebagai ukuran dalam sistem pendukung keputusan penerima beasiswa BBM mahasiswa STIKes Aisyah Pringsewu dengan model algoritma k-nearest neighbor, ditunjukan pada tabel 3.2 dan tabel 3.4.

Tabel 3.2 Data Testing Model Algoritma $K$ Nearest Neighbor

\begin{tabular}{|c|c|c|c|c|c|c|}
\hline Ipk & $\begin{array}{c}\text { emeste } \\
\mathrm{r}\end{array}$ & $\begin{array}{c}\text { Jumlah } \\
\text { Tanggung } \\
\text { an }\end{array}$ & $\begin{array}{c}\text { Penghasil } \\
\text { an }\end{array}$ & $\begin{array}{c}\text { Kwh } \\
\text { Listrik }\end{array}$ & $\begin{array}{c}\text { Kelaya } \\
\text { kan }\end{array}$ & $\begin{array}{c}\text { Nil } \\
\text { ai } \\
\mathrm{K}\end{array}$ \\
\hline 3, & 3 & 1 & $\begin{array}{c}4.000 . \\
000\end{array}$ & $\begin{array}{c}13 \\
00\end{array}$ & Layak & 10 \\
14 & & & & \\
\hline
\end{tabular}

Tabel 3.3 Data Baru Yang Akan Dicari

\begin{tabular}{|c|c|c|c|c|c|c|c|}
\hline IPK & $\begin{array}{c}\text { Nam } \\
\text { a } \\
\text { Mah } \\
\text { asisw } \\
\text { a }\end{array}$ & Ipk & $\begin{array}{c}\text { emest } \\
\text { er }\end{array}$ & $\begin{array}{c}\text { Tanggu } \\
\text { ngan }\end{array}$ & $\begin{array}{c}\text { Pengha } \\
\text { silan }\end{array}$ & $\begin{array}{c}\text { Kwh } \\
\text { Listri } \\
\mathrm{k}\end{array}$ & $\begin{array}{c}\text { Kelaya } \\
\text { kan }\end{array}$ \\
\hline $\begin{array}{c}1551 \\
1002 \\
4\end{array}$ & $\begin{array}{c}\text { Roya } \\
\text { nda } \\
\text { Kasi }\end{array}$ & $\begin{array}{l}3, \\
1 \\
4\end{array}$ & 3 & 1 & $\begin{array}{c}4.00 \\
0.00 \\
0\end{array}$ & $\begin{array}{l}1 \\
3 \\
0 \\
0\end{array}$ & ? \\
\hline
\end{tabular}

\subsubsection{Menghitung Jarak Euclidian}

\section{Berdasarkan Jumlah Data Training}

Menghitung jarak euclidian dapat dihitung dengan persamaan 3.3

$\mathrm{D}(\mathrm{a}, \mathrm{b})=$

$\sqrt{\sum_{k=1}^{d}\left(a_{k}-b_{k}\right)^{2}}$

\section{Keterangan}

a. Dimana $\mathrm{D}(\mathrm{a}, \mathrm{b})$ adalah jarak skalar dari dua buah obyek data a dan b yang berupa matriks berukuran d dimensi.

b. Dimensi d menggambarkan fitur yang digunakan dalam proses klasifikasi.

Proses Perhitunganya sebagai berikut :

$$
\mathrm{D} 1=
$$

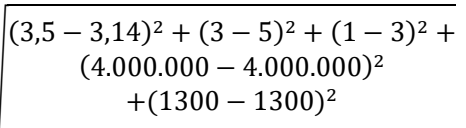




\subsubsection{Hasil Perhitungan Jarak Euclidian}

Setelah mencari perhitungan jarak euclidian tahap selanjutnya adalah pengurutan rangking berdasarkan nilai $\mathrm{K}$ pada algoritma k-nearest neighbor dimulai dari nilai yang terkecil, ditunjukan tabel 3.4.

\begin{tabular}{|c|c|c|}
\hline Data Ke-i & KELAYAKAN & JARAK \\
\hline 1 & TIDAK LAYAK & 2829709,18 \\
\hline 2 & TIDAK LAYAK & 4244490,12 \\
\hline 3 & LAYAK & 2829713,35 \\
\hline 4 & LAYAK & 2829716,43 \\
\hline 5 & LAYAK & 1415498,32 \\
\hline 6 & LAYAK & 1414864,81 \\
\hline 7 & TIDAK LAYAK & 4244492,47 \\
\hline 8 & LAYAK & 1414860,68 \\
\hline 9 & LAYAK & 1415500,17 \\
\hline 10 & TIDAK LAYAK & 2829713,21 \\
\hline 11 & LAYAK & 1415499,28 \\
\hline 12 & TIDAK LAYAK & 4243929,22 \\
\hline 13 & TIDAK LAYAK & 2829077,1 \\
\hline 14 & LAYAK & 1415497,3 \\
\hline 15 & LAYAK & 1415499,96 \\
\hline 16 & LAYAK & 2829713,59 \\
\hline 17 & TIDAK LAYAK & 2829717,81 \\
\hline 18 & LAYAK & 1414870,39 \\
\hline 19 & LAYAK & 2829712,49 \\
\hline 20 & LAYAK & 1415497,53 \\
\hline 21 & LAYAK & 1415500,02 \\
\hline 22 & TIDAK LAYAK & 5658702,82 \\
\hline 23 & TIDAK LAYAK & 4243929,22 \\
\hline 24 & TIDAK LAYAK & 2829077,1 \\
\hline 25 & LAYAK & 1415497,3 \\
\hline 26 & LAYAK & 1415499,96 \\
\hline 27 & LAYAK & 2829713,59 \\
\hline 28 & TIDAK LAYAK & 2829717,81 \\
\hline 29 & LAYAK & 1414870,39 \\
\hline
\end{tabular}

\begin{tabular}{|c|c|c|}
\hline 30 & LAYAK & 2829712,49 \\
\hline 31 & LAYAK & 1415497,53 \\
\hline 32 & LAYAK & 1415500,02 \\
\hline 33 & TIDAK LAYAK & 5658702,82 \\
\hline 34 & LAYAK & 1414864,81 \\
\hline 35 & TIDAK LAYAK & 4244492,47 \\
\hline 36 & LAYAK & 1414860,68 \\
\hline 37 & LAYAK & 1415500,17 \\
\hline 38 & TIDAK LAYAK & 2829713,21 \\
\hline 39 & LAYAK & 1415499,28 \\
\hline 40 & TIDAK LAYAK & 4243929,22 \\
\hline 41 & LAYAK & 2829713,59 \\
\hline 42 & TIDAK LAYAK & 2829717,81 \\
\hline 43 & LAYAK & 1414870,39 \\
\hline 44 & LAYAK & 2829712,49 \\
\hline 45 & LAYAK & 1415497,53 \\
\hline 46 & LAYAK & 1415500,02 \\
\hline 47 & TIDAK LAYAK & 5658702,82 \\
\hline 48 & LAYAK & 1414864,81 \\
\hline 49 & TIDAK LAYAK & 4244492,47 \\
\hline 50 & LAYAK & 1414860,68 \\
\hline
\end{tabular}

Dari hasil pengurutan data berdasarkan nilai jarak diatas, diambil sejumlah nilai $\mathrm{K}$, yaitu $\mathrm{K}=7$ dari data teratas (nilai jaraknya paling kecil) maka didapatkan hasil status menerima beasiswa sebagai berikut:

$$
\begin{array}{ll}
\text { 1. } & \text { LAYAK } \\
\text { 2. } & =7 \\
\text { TIDAK LAYAK }=3
\end{array}
$$

Setelah didapatkan hasil status menerima dan dibandingkan jumlahnya, maka diperoleh keputusan bahwa status kelayakan data ke 9 adalah "LAYAK" atau dapat menerima beasiswa.

\section{Simpulan}

Berdasarkan hasil penelitian yang telah dilakukan dapat disimpulkan beberapa hal sebagai berikut:

1. Metode K-Nearest Neighbor dapat diimplementasikan untuk membantu dalam seleksi calon penerima Bantuan Biaya Mahasiswa (BBM), dan hasil 
perhitungan yang diperoleh dari masing masing metode menghasilkan output yang sama.

2. Model ini bisa dijadikan sebagai referensi pihak STIKes Aisyah Pringsewu dalam seleksi calon penerima Bantuan Biaya Mahasiswa (BBM) dengan lebih akurat.

3. Tingkat akurasi Nearest Neighbor dalam menentukan penerima beasiswa BBM adalah $80 \%$.

\section{Daftar Pustaka}

[1] Kusrini. 2007. Konsep dan Aplikasi Sistem

Keputusan.Yogyakarta : ANDI

[2] Hafiz, A., \& Ma'mur, M. 2018. Sistem Pendukung Keputusan Pemilihan Karyawan Terbaik Dengan Pendekatan Weighted Product. Jurnal Cendikia, 15(1 April), 23-28.

[3] Rizki Alfiasca, Pantjawati, Sudarmaningtyas. 2014. Rancang Bangun Sistem Informasi Manajemen Arsip Rumah Sakit Bedah Surabaya Berbasis Web. JSIKA Vol 3, No 1. STMIK STIKOM Surabaya.

[4] Ambrowati, Armadiyah,

"SistemPendukung Keputusan

Pemilihan Karyawan Berprestasi Berdasarkan Kinerja dengan Metode AHP" dalam Seminar Nasional Aplikasi Teknologi Informasi (SNATI 2007). Jogjakarta : Jurusan Teknik Informatika Universitas Islam Indonesia, 2006.

[5] Rika yunitarini. TOPSIS (Technique Andrian, Indarto, Abdiansah. 2008 . Sistem Penalaran Komputer Berbasis Kasus (Case Based Reasoning-CBR). Ardana Media. Yogyakarta.

[6] Ferdi Firdaus, Mahmud Imrona, Angelina Prima Kurniati. 2009. "Analisis Dan Implementasi Sistem Pendukung PengambilanKeputusan Menggunakan Pendekatan Case Based ReasoningDalam Penerimaan Beasiswa Di It Telkom". Jurnal Teknologi Informasi dan Ilmu Komputer.
[7] Kusrini, Emha Taufik Lutfi. 2009. Algoritma Data Mining. Penerbit Andi Offset, Yogyakarta.

[8] Andrian, Indarto, Abdiansah. 2008 . Sistem Penalaran Komputer Berbasis Kasus (Case Based Reasoning-CBR). Ardana Media. Yogyakarta. 